\title{
Brain Blood Flow in the Neurological Determination of Death: Canadian Expert Report
}

\author{
Sam D. Shemie, Donald Lee, Michael Sharpe, Donatella Tampieri and Bryan \\ Young, on behalf of the Participants in the Expert Consensus Meeting on Brain \\ Blood Flow in the Neurological Determination of Death. Endorsed by the \\ Canadian Critical Care Society
}

\begin{abstract}
The neurological determination of death (NDD, brain death) is principally a clinical evaluation. However, ancillary testing is required when there are factors confounding the clinical determination or when it is impossible to complete the minimum clinical criteria. At the time of the 2003 Canadian Forum clarifying the criteria for brain death, 4-vessel cerebral angiography or radionuclide angiography were the recommended tests and the electroencephalogram was no longer supported. At the request of practitioners in the field, the Canadian Council for Donation and Transplantation sponsored the assembly of neuroradiology and neurocritical care experts to make further recommendations regarding the use of ancillary testing. At minimum, patients referred for ancillary testing should be in a deep unresponsive coma with an established etiology, in the absence of reversible conditions accounting for the unresponsiveness and the clinical examination should be performed to the fullest extent possible. For newborns, children and adults, demonstration of the absence of brain blood flow by following recommended imaging techniques fulfill the criteria for ancillary testing: 1. radionuclide angiography or CT angiography 2. traditional 4-vessel angiography 3. Magnetic resonance angiography or Xenon CT. In the absence of neuroimaging, an established cardiac arrest, as defined by the permanent loss of circulation, fulfills the ancillary criteria for the absence of brain blood flow. Acknowledging the existing limitations in this field, further research validating current or evolving techniques of brain blood flow imaging are recommended.
\end{abstract}

RÉSUMÉ: Perfusion cérébrale pour la détermination neurologique de la mort : rapport d'un groupe d'experts canadiens. La détermination neurologique de la mort (DNM, mort cérébrale) est basée principalement sur une évaluation clinique. Cependant, on doit avoir recours à des tests accessoires quand il existe des facteurs confondants ou quand les critères cliniques minimaux ne sont pas satisfaits. Au moment du Forum canadien de 2003, qui a précisé les critères de la mort cérébrale, on recommandait l'angiographie cérébrale de 4 vaisseaux ou l'angiographie isotopique. L'électroencéphalographie n'était plus recommandée. À la demande de médecins travaillant dans ce domaine, le Conseil canadien pour le don et la transplantation a parrainé un groupe d'experts en neuroradiologie et en soins intensifs neurologiques dont le mandat était de formuler des recommandations sur l'utilisation de tests accessoires. Les patients référés devraient être en coma profond, avec absence de réponse, dont l'étiologie est connue, sans pathologie réversible expliquant l'absence de réponse, et dont l'examen clinique a été exhaustif. Pour les nouveau-nés, les enfants et les adultes, la démonstration de l'absence de flux sanguin cérébral remplit le critère pour l'utilisation de tests accessoires : 1. l'angiographie isotopique ou l'angiographie par tomodensitométrie; 2. l' angiographie sélective de 4 vaisseaux; 3. l'angiographie par résonance magnétique ou la tomodensitométrie au xénon. Sans neuroimagerie, l'arrêt cardiaque avéré, tel que défini par l'absence permanente de circulation, remplit le critère accessoire pour l'absence de flux sanguin cérébral. Étant donné les limites actuelles dans ce domaine, nous recommandons de poursuivre la recherche afin de valider les techniques actuelles d'imagerie du flux sanguin cérébral ou celles qui sont en développement.

Can. J. Neurol. Sci. 2008; 35: 140-145

In April 2003, the Donation Committee of the Canadian Council for Donation and Transplantation (CCDT) organized a forum entitled "Severe Brain Injury to Neurological Determination of Death". This forum addressed the variability in the recognition, diagnosis, and documentation of brain death and provided recommendations for minimum practice standards for the neurological determination of death (NDD). ${ }^{1}$ These recommendations have been widely endorsed and implemented in Canada.
From the Division of Critical Care Medicine (SDS), Montreal Children's Hospital, Department of Radiology (DT), Montreal Neurological Hospital \& Institute, McGil University Health Centre, Montreal, QC; Bertram Loeb Chair in Organ and Tissue Donation, Faculty of Arts (SDS), University of Ottawa, Ottawa; Radiology Department (DL), Department of Anaesthesia and Perioperative Medicine (MS), Department of Clinical Neurological Sciences (BY), London Health Sciences Centre, University of Western Ontario, London, Ontario, Canada.

Received October 11, 2007. Final Revisions Submitted December 18, 2007. Reprint requests to: Sam D. Shemie, Division of Pediatric Critical Care, Extracorporeal Life Support Program, Montreal Children's Hospital, McGill University Health Centre, McGill University, 2300 Tupper Street, Room c806, Montreal, Quebec, H3H 1P3, Canada. 
Neurological determination of death remains principally and fundamentally a clinical evaluation and the clinical examination is necessary in all cases. However, ancillary testing is required when there are factors confounding the clinical determination or when it is impossible to complete the minimum clinical criteria. Tests demonstrating the absence of intracranial blood flow were recommended, and the electroencephalogram is no longer supported. ${ }^{1,2}$ At the time of the Forum, the tests considered validated for this purpose were 4-vessel cerebral angiography and radionuclide angiography.

Practitioners in the field have identified the inability to access currently recommended techniques to evaluate cerebral blood flow for the NDD in all hospitals and/or at all times. The inaccessibility of these techniques impedes the ability to confirm the diagnosis of brain death. The Canadian Critical Care Society, the Intensive Care Unit (ICU) Advisory Group of Trillium Gift of Life Network, and individual ICU practitioners have requested guidance. The Donation Committee of the CCDT assembled an expert group to review literature in this area and to discuss, evaluate, and consider the validity of alternative tests. This meeting represents the first step in a process of updating recommendations and guidelines to reflect current medical knowledge and the needs of medical practitioners.

The Expert Consensus Meeting on Brain Blood Flow (BBF) in the Neurological Determination of Death was held in Montréal, Quebec, on Thursday, November 16, 2006. Sponsored by the CCDT, it brought together 17 participants and speakers from across Canada (Appendix) with the following objectives:

1. To determine the distinction between tests of intracerebral blood flow, brain blood flow, intracranial blood flow, and brain perfusion;

2. To determine which tests of blood flow and perfusion are acceptable for NDD and to provide recommendations on preferred tests;

3. To establish minimal standards for technology, technologist, and interpreter expertise;

4. To address issues of clinical criteria and ancillary testing that were not fully articulated by the 2003 CCDT NDD recommendations; and

5. To identify important areas of research in ancillary testing for the NDD.

\section{Meeting STRUCture}

Those who attended the meeting were invited to participate as experts in their fields and agents of change. They represented all regions of Canada and included experts in adult/pediatric neurointensive care and neuroradiology (Appendix). After each expert presentation (Appendix), there was a question and answer period. Participants were then separated into three groups to address key questions related to BBF in the NDD. Each group selected a facilitator to keep people on track and a recorder to reflect agreement by group members and prepare a brief plenary report.

The initial three groups were arranged with a representative mix of neuroradiology and neurocritical care experts blended in each group, to answer questions in the following categories:

- Nomenclature and concepts (recommendation 1)

- Research recommendations for gold standards and validity in brain blood flow testing for the neurological determination of death (recommendation 10)
Participants were then organized into three different groups based on specialization: two groups of neuroradiology experts and one neurocritical care group. The neuroradiology groups addressed questions related to tests of brain blood flow in the NDD:

- Brain blood flow imaging modalities (recommendation 2)

- Standards for brain blood flow imaging (recommendation 3)

- $\quad$ Pediatric considerations (recommendation 4)

- $\quad$ Brainstem blood flow (recommendation 5)

- Cardiac arrest and brain blood flow (recommendation 6)

The neurocritical care group addressed questions related to:

- Clinical criteria and ancillary testing (recommendation 7):

- Brain blood flow tests prior to clinical determinations (recommendation 8)

- Barbiturate use in refractory intracranial hypertension, clinical criteria, and apnea testing (recommendation 9)

Each section was followed by a brief presentation by the groups, during which participants discussed and came to agreement (wherever possible) on the questions at hand and suggested areas for further exploration. Participants' comments and recommendations were gathered by the report writer. After the draft report on the discussions and recommendations made at the meeting had been reviewed by all participants and their suggestions have been incorporated, a final draft was prepared.

\section{Clinical Context and the Definition of Neurological Determination of Death}

Clinical criteria have primacy in the NDD and are defined as follows: ${ }^{1}$

- Established etiology capable of causing neurological death in the absence of reversible conditions capable of mimicking neurological death

- Deep unresponsive coma

- Absent brainstem reflexes as defined by absent gag and cough reflexes and the bilateral absence of:

- motor responses, excluding spinal reflexes

- corneal responses

- $\quad$ pupillary responses to light with pupils at mid size or greater and

- $\quad$ vestibulo-ocular responses

- Absent respiratory effort based on the apnea test

- Absent confounding factors

For the purposes of organ donation, the NDD has the following requirements:

- Two physicians perform the examination

- There is no prescribed interval between determinations (except where age-adjusted criteria apply)

- The first and second physician determinations may be performed concurrently

- If the determinations are performed at different points in time, a full clinical examination, including apnea testing, must be performed at each determination

An ancillary test should be performed when the full clinical criteria cannot be completed. At minimum, the following two criteria must be met prior to performing an ancillary test:

- Established etiology in the absence of reversible conditions

- Deep unresponsive coma 


\section{Nomenclature AND ConcePTS}

\section{Preamble}

Brain blood flow imaging detects flow in the vasculature of the brain and may refer to large (early phase) and small (late phase) vessels. Techniques can be sensitive to early phase only (angiography) or both early and late phase (perfusion). Because of the simplicity in modeling, inert non-diffusible tracers are best suited for determination of both blood flow and measurement of perfusion. Both computed tomography (CT) and magnetic resonance (MR) are amenable to such studies, thus distinguishing CT or MR angiography from CT or MR perfusion studies. If there is no visualization of major arteries, there should be no distal perfusion. Brain tissue uptake of the tracer, as seen with hexamethylpropylene-amine oxime (HMPAO) radionuclide testing, is a reflection of blood flow, perfusion, and neuronal function. ${ }^{3}$

\section{Recommendation 1:}

1.1 Brain blood flow is the preferred terminology for ancillary testing in the NDD.

1.2 Absence of brain blood flow is the imaging and physiological correlate of brain arrest and brain death. From an imaging point of view, brain blood flow refers to intraarterial filling and the visualization of large vessels (internal carotid, basilar, middle cerebral, anterior cerebral and posterior cerebral arteries) in the cerebral hemispheres and posterior fossa structures (brainstem and cerebellum).

1.3 Demonstration of the absence of brain blood flow by recommended imaging techniques fulfill the criteria for ancillary testing in the NDD (refer to recommendation 2).

1.4 In ancillary test reporting, neuroradiologists should avoid the terminology "consistent with brain death" and should only comment on the presence or absence of brain blood flow.

\section{Key Considerations}

- The term "ancillary" should be understood as an alternative test to the clinical determination, that otherwise, for any reason, cannot be conducted.

- The confirmation of brain death by ancillary testing should be clear and distinguished from other forms of severe, irreversible brain injury such as neuro-vegetative states or death without recovery of consciousness (severe brain injury without brain death).

- 'Cerebral' blood flow is a misnomer, as it strictly refers to the cerebral hemispheres and does not include posterior fossa structures.

- There is an anatomical distinction between intracranial and intracerebral compartments and corresponding blood flow to those compartments. As an ancillary test in the NDD, brain blood flow should be absent in the large vessels of the cerebral hemispheres and posterior fossa structures. However, blood flow to the portion of the intracranial space that lies exterior to the surface of the brain, but interior to the cranium, may still be detectable. This does not contradict the diagnosis.

- Absence of brain blood flow is based on the failure to opacify the intracerebral arteries. There is no need to consider the venous phase in this clinical setting.
- Tests of brain perfusion should be distinguished from tests of brain blood flow. For the purpose of the NDD, the absence of brain blood flow confirms the NDD. Demonstration of the absence of tissue perfusion or tissue uptake is not required.

- Assessment of tissue perfusion or uptake is not necessary for confirmation of death, but in instances where ancillary testing capable of detecting tissue perfusion and uptake (e.g., nuclear techniques) has been performed, tissue perfusion and uptake must be absent for confirmation of death. The presence of tissue perfusion/uptake in the absence of demonstrable brain blood flow may arise in the remote circumstance of unexpected collateral blood flow or flow detection below the lower limits of that test.

Tests of Brain Blood Flow in the Neurological Determination of Death (NeUroradiology Experts)

\section{Preamble}

Refer to the accompanying review by Heran et al entitled "Potential Ancillary Tests in the Evaluation of Brain Death: The Value of Brain Blood Flow Assessment". ${ }^{4}$

\section{Brain Blood Flow Imaging Modalities}

\section{Recommendation 2:}

2.1 Recommended tests (in order of preference):

- radionuclide angiography or CT angiography

- $\quad$ traditional 4-vessel angiography

- MR angiography or Xenon CT

2.2 Tests that are not recommended:

- $\quad$ CT perfusion, MR perfusion, and transcranial Doppler

\section{Key Considerations}

- Radionuclide angiography and CT angiography are preferentially recommended and rated equally.

- CT angiography is recommended as a preferred test because of its accessibility, simplicity, widespread use, ease of interpretation, reproducibility, and experience in many forms of brain injury. This is based on expert neuroradiology consensus extrapolated from other forms of brain injury and cerebrovascular imaging. There is a large volume of experiential clinical data where CT angiography demonstrates brain blood flow in diverse forms of severe brain injury (in the absence of neurological death) ${ }^{5}$

- Nephrotoxic contrast agents are the same in CT as in traditional 4-vessel angiography. CT angiography contrast volumes and corresponding risks for nephrotoxicity will vary according to the slice resolution of the scanner.

- MR angiography is also recommended but has limitations regarding access and ease of use in ventilated ICU patients.

- Xenon CT is sensitive and specific but is not routinely available.

- $\quad$ CT perfusion is not widely available and remains a research tool at this stage.

- Transcranial Doppler is not recommended due to its operator dependency and potential false positive and negative rate; however, if no flow is demonstrated it may be useful as a portable bedside test to determine whether other forms of blood flow testing are indicated. 
- Radiation exposure in CT is to the head only, whereas nuclear angiography exposure is to the whole body.

- In brain death with or without potential organ donation, radiation exposure isolated to the head is not a relevant issue. Radiation exposure to the whole body is of unclear significance and uncertain impact on transplantable organs.

\section{STANDARDS FOR BRAIN BLOOD FloW IMAGING}

\section{Recommendation 3:}

3.1 Radionuclide angiogram:

- The current recommended standards apply. ${ }^{6}$

3.2 CT angiography:

- The minimum technology required is a spiral CT and the technologist should have experience in CT angiography.

- It must be possible to track the contrast bolus into the aorta and visualize, at minimum, the common carotid artery bifurcation extending to the skull base.

- $\quad$ Patient baseline physiology similar to a nuclear study (i.e., absence of shock and hypotension $)^{1}$ is required.

3.3 For all forms of brain blood flow testing, the staff radiologist or his/her designate should provide the initial interpretation, with the staff radiologist responsible for the initial interpretation provided by the designate. The staff radiologist is responsible for the final report.

\section{Key Considerations}

- $\quad$ Experience in CT angiography can be broadly defined as a minimum of $100 \mathrm{CT}$ angiograms of the brain and neck (from the aortic arch upwards) in addition to familiarity with pump injections and appropriate timing of scans.

\section{Pediatric Considerations}

\section{Recommendation 4:}

Neurological determination of death recommendations for newborns, infants, and children were similar to adults, and ancillary testing is not routinely recommended. Neurological determination of death is a clinical evaluation; if the clinical criteria cannot be completed or in the setting of confounding factors, tests demonstrating absent brain blood flow are recommended (Recommendation 2.1) as the ancillary testing for newborns, infants and children.

\section{Key Considerations}

- $\quad$ NDD remains a clinical determination in these age groups. Data are currently inadequate to verify or demonstrate the correlation between clinical assessment for brain death and imaging modalities in this area. The nature of this relationship is of particular relevance in the infant and newborn population, where the skull is relatively compliant. It is acknowledged that in situations where ancillary testing is required (confounding conditions or inability to complete the minimum clinical criteria), the presence of brain blood flow in children who may have been brain dead on clinical grounds may occur because of the increased compliance of the skull. Demonstration of the presence of brain blood flow under these circumstances contravenes the diagnosis of death.

\section{BRAINSTEM BLOOD FLOW}

\section{Preamble}

The CCDT NDD recommendations in $2003^{1}$ include both whole brain death concepts as well as isolated but complete brainstem death that may theoretically occur with some residual supratentorial blood flow or electrical function.

\section{Recommendation 5:}

This expert group could not identify any tests (current or in evolution) capable of demonstrating the absence of blood flow to the brainstem in isolation.

\section{Key Considerations}

- Similar to the 2003 recommendations, it is acknowledged that no ancillary tests currently exist that can detect the absence of brainstem blood flow in isolation. However, practitioners occasionally encounter cases of complete and irreversible loss of brainstem function due to mechanisms other than terminal elevation of intracranial pressure (e.g., massive brainstem infarction in the absence of severe hydrocephalus). In these instances, if clinical criteria cannot be completed and ancillary testing is performed, brain blood flow to supratentorial regions may be present thus negating the determination of death by neurological criteria.

\section{Cardiac Arrest and Brain Blood Flow}

\section{Recommendation 6:}

In circumstances when cardiopulmonary resuscitation is not or will not be provided, an established cardiac arrest, as defined by pulselessness and the permanent loss of circulation fulfills the ancillary criteria for the absence of brain blood flow.

\section{Clinical Criteria and Ancillary Testing (Neurocritical Care Experts)}

\section{Preamble}

In the 2003 CCDT NDD recommendations ${ }^{1}$ the following overarching recommendation was made: "Existing provincial and territorial laws indicate that for the purposes of a post mortem transplant, the fact of death shall be determined by at least two physicians in accordance with accepted medical practice. The first and second physicians' determinations, required by law, may be performed concurrently. However, if the determinations are performed at different points in time, a full clinical examination, including apnea testing, must be performed at each determination"

Neurological determination of death remains principally and fundamentally a clinical determination and the clinical exam has primacy. When it is possible to perform the full clinical determination in the absence of confounding conditions, this includes the apnea test and no ancillary testing is required. However, ancillary testing is required when there are factors confounding the clinical determination or when it is impossible to complete the minimum clinical criteria. 


\section{Recommendation 7:}

Additional indications for ancillary testing that were not fully addressed by the CCDT NDD recommendations include the following:

- Physician and/or family discomfort with the results of the clinical determination

- Presence of residual movements or spinal reflexes that are subject to differing interpretation by clinicians performing the determination

\section{Brain Blood Flow Tests Prior to Clinical DETERMINATIONS \\ Preamble}

Occasionally, the full clinical criteria for the NDD cannot be completed, due to congenital or acquired (eg. ocular trauma) anatomic abnormalities or in the presence of confounding conditions (see barbiturate use below) that make the determination unreliable. In these instances, an ancillary test should be performed, assuming the remainder of the two clinical examinations has been completed to the fullest extent possible. It is recognized that ancillary testing may be most feasible before both appropriate clinical examinations can be completed. At minimum, patients referred for ancillary testing should be in deep unresponsive coma with an established etiology, in the absence of reversible conditions accounting for the unresponsiveness.

\section{Recommendation 8:}

If the absence of brain blood flow has been demonstrated prior to the completion of a first clinical determination or after a first clinical determination but prior to the completion of a second clinical determination, it is necessary to perform all of the minimum clinical criteria, including an apnea test, when it is possible to do so.

\section{Key Considerations}

- If confounding factors exist, or it is impossible to complete all the minimum clinical criteria, each clinical examination should be performed to the fullest extent possible and this includes an apnea test wherever it is possible to do so.

- If the apnea test is perceived to be of excessive risk because of hemodynamic and/or respiratory instability, this is considered to be a confounding factor. In this circumstance, the apnea test should not be done, and an ancillary test must be performed.

- In the circumstance where the absence of brain blood flow has been shown by imaging prior to the clinical determination, the clinical exam should still be performed fullest extent possible. Demonstrating absent brain blood flow is not sufficient for the diagnosis of death when all clinical criteria (including apnea testing) can be performed and provided they can be done so without excessive risk.

\section{Barbiturate USE IN REFraCtORY INTRACRANIAL Hypertension, Clinical Criteria, and Apnea Testing \\ Preamble}

In the 2003 CCDT NDD recommendations, ${ }^{1}$ the following key consideration was made:
"Existing evidence, although not firmly established, suggests that for patients who may fulfill minimum clinical criteria under the circumstances of high-dose barbiturate therapy utilized for refractory intracranial hypertension to achieve deep coma or electrocerebral silence, NDD can be confirmed by the demonstration of absent intracranial blood flow."

Practitioners have requested further guidance regarding the necessity of a full clinical examination that includes apnea testing under these circumstances.

\section{Recommendation 9:}

If electrocerebral silence has been confirmed by electroencephalogram while on high-dose barbiturates for refractory intracranial hypertension, no apnea test is required as part of the clinical examination. However, if there is uncertainty surrounding the depth or level of barbiturate-induced coma, a full exam should be performed, including an apnea test.

\section{Key Considerations}

- Performance of an apnea test in this circumstance can guide the use of brain blood flow imaging. The demonstration of respiratory effort is contrary to the diagnosis of the NDD and thus ancillary testing would not be indicated.

- In the absence of demonstrated electrocerebral silence, clinical determinations including apnea testing are required.

RESEARCH RECOMMENDATIONS FOR Gold STANDARDS AND VAlidity IN BRAIN BLOOD Flow TESTING FOR THE Neurological Determination of DEATH

\section{Preamble}

The Forum acknowledged the limitations in existing evidence in this field and the difficulties of performing prospective research in patients around the time of death. It is recognized that existing ancillary tests that were previously considered as validated gold standards have not been subjected to rigorous evaluation. The preceding recommendations were based on existing literature and expert consensus. In light of evolving techniques in this field, recommendations for future investigations were made. A guiding principle should be the absence of false positives (i.e., all patients who demonstrate no brain blood flow should be brain dead).

\section{Recommendation 10:}

10.1 Methods for validating current or evolving techniques of brain blood flow imaging or measurement that are recommended (unanimous agreement):

- Confirmation by comparison to an ancillary "gold standard", currently cerebral angiography and radionuclide scanning (HMPAO or single photon-emission CT)

- Research-based initiatives to confirm validity, as defined by prospective human studies in recently dead patients who demonstrate

- the absence of brain blood flow in clinically brain dead patients, and

- the presence of brain blood flow in those with severe brain injury who do not fulfill the criteria for brain death 
10.2 Methods for validating current or evolving techniques of brain blood flow imaging or measurement that are recommended (majority agreement, but not unanimous):

- Expert consensus from the neuroradiology community

- Testing after clinical brain death criteria in a series of patients

10.3 Methods for validating current or evolving techniques of brain blood flow imaging or measurement that are not recommended:

- $\quad$ Should evolve into practice in a manner similar to cerebral angiography and radionuclide scanning, based on clinical application

- Confirm that the test allows detection of blood flow above the viability threshold for perfusion (i.e., $>10 \mathrm{ml} / 100 \mathrm{gm}$ of brain tissue/min)

\section{Key Considerations}

- Organ procurement agencies should record and report the frequency, type and results of ancillary testing in the NDD.

- Further validation research from the neuroradiology community is suggested to confirm these expert recommendations (e.g., prospective cohort of patients requiring ancillary testing comparing radionuclide angiography to CT angiography).

\section{REFERENCES}

1. Shemie SD, Doig C, Dickens B, Byrne P, Wheelock B, Rocker G, et al. Severe brain injury to neurological determination of death: Canadian forum recommendations. CMAJ. 2006;174(6):S1-12.

2. Young B, Shemie SD, Doig C, Teitelbaum J. Brief review: the role of ancillary tests in the neurological determination of death. Can J Anes. 2006;53(6):620-7.

3. Weckesser M, Schober O. Brain death revisited: utility confirmed for nuclear medicine. Eur J Nucl Med. 1999;26:1387-91.

4. Heran MKS, Heran NS, Shemie SD. A review of ancillary tests in evaluating brain death. Can J Neurol Sci. (in press) 2008.

5. Murphy BD, Fox AJ, Lee DH, Sahlas DJ, Black SE, Hogan MJ, et al. Identification of penumbra and infarct in acute ischemic stroke using computed tomography perfusion-derived blood flow and blood volume measurements. Stroke. 2006;37:1771-7.

6. Donahoe KJ, Frey KA, Gerbaudo VH, Mariani G, Nagel JS, Shulkin G. Society of Nuclear Medicine Procedure Guideline for Brain Death Scintography. February 25, 2003.

\section{APPENDIX}

\section{Planning Committee}

Dr. Sam Shemie, Meeting Chair, Pediatric Critical Care, Montreal Children's Hospital, McGill University Health Centre, Chair, Donation Committee, CCDT, Bertram Loeb Chair in Organ and Tissue Donation, Faculty of Arts, University of Ottawa , Montréal, Que., Dr. Donald Lee, Radiology Department, London Health Sciences Centre, President, Canadian Association of Neuroradiologists, London, Ont., Dr. Michael Sharpe, Department of Anaesthesia and Perioperative Medicine, London Health Sciences Centre, Program in Critical Care, University of Western Ontario, London, Ont., Dr. Donatella Tampieri, Department of Radiology, Montreal Neurological Hospital \& Institute, Montréal, Que., Dr. Bryan Young, Department of Clinical Neurological Sciences, London Health Sciences Centre, Neurology, University of Western Ontario, London, Ont.

\section{Participant List}

Dr. Suzanne Fontaine, Neuroradiology, Hôpital Saint-Luc du CHUM, Université de Montréal, Montréal, Que.; Dr. Cameron Guest, Adult Critical Care, Sunnybrook Health Science Centre, Chief Medical
Officer, Trillium Gift of Life Network, Toronto, Ont.; Dr. Mark Hamilton, Neurosurgeon, Alberta Children's Hospital, Department of Clinical Neurosciences, University of Calgary, Past President, Canadian Neurosurgical Society, President, Canadian Neurological Sciences Federation; Dr. Manraj Heran, Adult/Pediatric Neuroradiology, Vancouver General Hospital, Vancouver, BC; Dr. Draga Jichici, Neurocritical Care, Hamilton Health Sciences Center, President, Canadian Neurocritical Group, Co-Chair, Canadian Neurocritical Care Society, Hamilton, Ont.; Dr, Stephan Langevin, AnesthesiologisteIntensivist, Hôpital l'Enfant-Jésus, Assistant Medical Director, QuébecTransplant, Quebec City, Que.; Dr. Donald Lee, Radiology Department, London Health Sciences Centre, President, Canadian Association of Neuroradiologists, London, Ont.; Dr. Ting-Yim Lee, Scientist, Imaging Program, Lawson Health Research Institute, Department of Diagnostic Radiology \& Nuclear Medicine, University of Western Ontario, London, Ont.; Dr. Vivek Mehta, Pediatric/Adult Neurosurgeon, Residency Training Director, University of Alberta Hospital, Medical Director, HOPE , Edmonton, Alta.; Dr. Joe Pagliarello, Critical Care and Surgery, The Ottawa Hospital, President, Canadian Critical Care Society, Ottawa, Ont.; Dr. Michael Sharpe, Department of Anaesthesia and Perioperative Medicine, London Health Sciences Centre, Program in Critical Care, University of Western Ontario, London, Ont.; Dr. Sam Shemie MD, Pediatric Critical Care, Montreal Children's Hospital, McGill University Health Centre, Chair, Donation Committee, CCDT, Montréal, Que.; Dr. I. Scott Sutherland, Neuroradiology, Health Sciences Centre, Winnipeg, Man.; Dr. Sean Symons, Division Head, Neuroradiology, Sunnybrook Health Science Centre, Division of Neuroradiology, Department of Medical Imaging, University of Toronto, Toronto, Ont.; Dr. Donatella Tampieri, Department of Radiology, Montreal Neurological Hospital \& Institute, Montréal, Que.; Dr. Robert Willinsky, Neuroradiology, Department of Medical Imaging, Toronto Western Hospital, Toronto, Ont.; Dr. Bryan Young, Department of Clinical Neurological Sciences, London Health Sciences Centre, Neurology, University of Western Ontario, London, Ont.

\section{Expert Speakers}

Part of the meeting agenda was dedicated to presentations from medical experts in order to enable participant learning and understanding. They are listed below in the order in which they appeared on the agenda: Sam D. Shemie, MD "Neurological Determination of Death and Historical Context". Ting-Yim Lee, PhD "The Scientific Basis of Cerebral Blood Flow Measurements and Imaging: Lessons Learned from Stroke Models". Manraj Heran, MD "Potential Ancillary Tests in the Evaluation of Brain Death".

\section{Participating Organizations}

Canadian Association of Neuroradiologists, Canadian Council for Donation and Transplantation, Canadian Critical Care Society, Canadian Neurocritical Group, Canadian Neurocritical Care Society, Canadian Neurological Sciences Federation, Canadian Neuroradiology Group, Canadian Neurosurgical Society, Québec-Transplant, Trillium Gift of Life Network.

\section{Sponsored by}

The Canadian Council for Donation and Transplantation

\section{Leadership}

Christina Rogers, Director of Initiatives, CCDT, Tracy Brand, Director if Initiatives, CCDT

Initiative Support

John Harkins, Sr. Administrative Assistant 